\title{
Excessive drinking in rats' adaptation to the schedule of feeding ${ }^{1}$
}

JAMES H. REYNIERSE AND DOUGLAS SPANIER ${ }^{2}$ UNIVERSITY OF NEBRASKA

Adaptation to the schedule of feeding as a requirement for the gradual development of polydipsia in rats was examined and rejected.

Schedule induced polydipsia, originally described by Falk (1961a, 1961b) has been interpreted as due to adventitious reinforcement (Clark, 1962; Segal, 1965). Stein (1964) found little supporting evidence for an adventitious reinforcement explanation and as an alternative suggested that rats have a tendency to drink after eating dry food. According to this idea, typical experimental schedules of reinforcement provide rats with many meals and therefore increase the number of drinking periods. On the other hand, when large quantities of food are available, meals are larger but the number of meals, and subsequently drinking periods, may be fewer.

Although drinking stopped immediately when a liquid milk reinforcer was substituted for dry pellets (Stein, 1964) and when a liquid oll was used (Stricker \& Adair, 1966), Falk (1967) showed that the effect could be obtained with liquid reinforcement while dry food was neither a necessary nor sufficient condition for the development of polydipsia. Similarly, the characteristic increase in water consumption over sessions before the full effect occurs (Reynierse, 1966; Stricker \& Adair, 1966) may also reflect the inadequacy of the induced thirst hypothesis. In this connection, Reynierse (166) suggested that a rat may require time to adapt to a particular schedule of reinforcement or feeding, thus accounting for the gradual development of polydipsia. The present investigation examines whether or not the gradual development of excessive drinking is due to adaptation to the schedule of feeding.

Subjects

The Ss were 12 adult, male albino rats of the Holtzman strain.

\section{Apparatus}

Ss were kept in individual wire rat cages for the duration of the experiment. A drinking spout (1/8 in. diameter orifice) attached to a calibrated reservoir was mounted on the front wall of each cage. Each spout was located 2 in. above the cage floor, approximately 3 in. from a floor mounted food cup. Pellets were delivered manually to the cup through an externally mounted delivery system consisting of a small funnel, 1/2 in. Tygon and copper tubing.

\section{Precedure}

With water available ad lib, daily water intake was recorded for seven consecutive days. Thereafter, each $S$ was given $8045-\mathrm{mg}$ Noyes pellets on each of 13 days. Pellets were presented manually on a noncontingent feeding schedule, individual pellets being presented irregularly around a mean of $40 \mathrm{sec}$ over a $1 \mathrm{~h}$ feeding period. The pellet diet was supplemented by two Lab-Blox per day presented approximately $5 \mathrm{~min}$ after the last pellet was delivered. During the first seven days, six Ss always had water available while the remaining six Ss had water avallable ad lib except during the hour feeding period, 1.e., when the pellets were individually delivered. During the last six days, all Ss had access to water at all times. Water intake was recorded for the $1 / 2 \mathrm{~h}$ period before, the $1 \mathrm{~h}$ period during, and the $1 \mathrm{~h}$ period after the distributed pellet feeding schedule.

\section{Resulis}

Figure 1 summarizes the mean dally water intake when water was available ad lib as well as the water intake for the $1 / 2 \mathrm{~h}$ period before and $1 \mathrm{hr}$ period after the pellet feeding schedule. Approximately 25 to $30 \mathrm{cc}$ of water were consumed daily and although level of water intake was reasonably stable, day to day fluctuations occurred ( $F=3.959, \mathrm{df}=6 / 60, p<.01)$. In general, insignificant levels of water intake occurred immediately before and after eating pellets. The single exception, occurring during the $1 \mathrm{~h}$ period following eating distributed pellets when water was unavailable during the pellet feeding schedule, yielded significantly higher levels of water intake ( $F=436.45$,

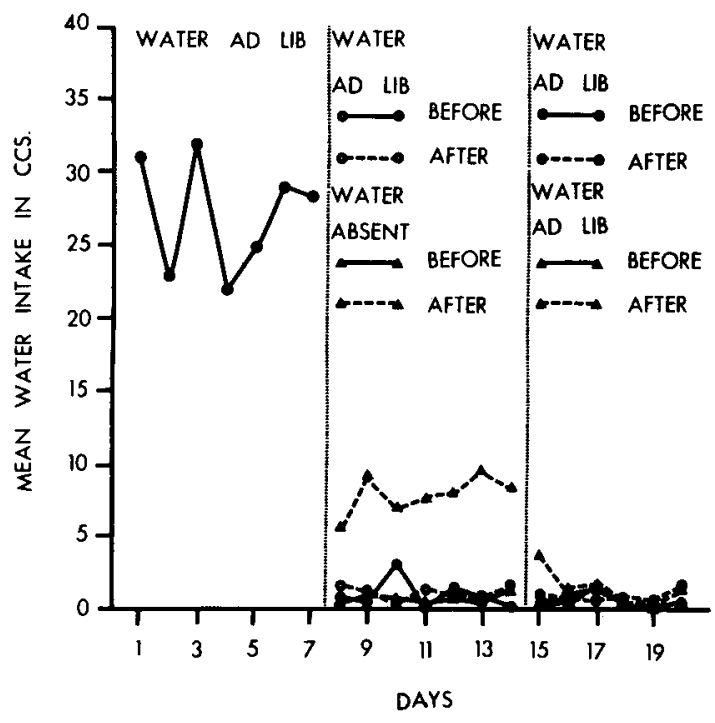

Fig. 1. Mean water intake for daily, 1/2 h before and $1 \mathrm{~h}$ after the pellet feeding schedule. 


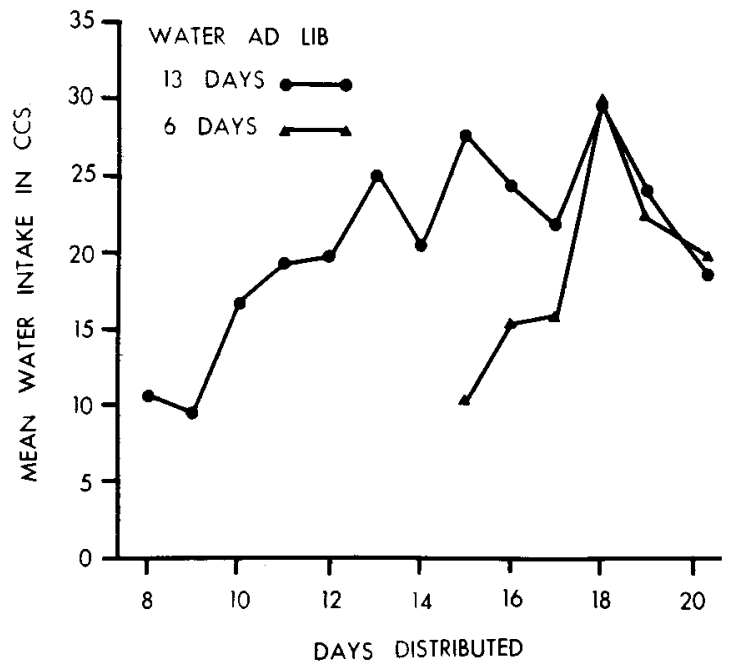

Fig. 2. Mean water intake during the $1 \mathrm{~h}$ pellet feeding schedule. The 13-day group had continuous access to food and water during this period. The 6-day group was exposed to the feeding schedule for 13 days but water was available during eating only on the last six days.

$\mathrm{df}=1 / 10, \mathrm{p}<.01)$ which only depended upon the earlier unavailability of water. Drinking during this period disappeared as soon as water was introduced during the pellet feeding schedule.

Figure 2 summarizes the mean water intake for both groups during the hour when pellets and water were simultaneously available. The 13-day group received water ad lib for 13 days and shows a characteristic gradual increase in water consumption, reaching asymptote at five or six days. The 6-day group was exposed to the feeding schedule for 13 days but water was available during eating only on the last six days. This group, too, shows a gradual increase in water consumption, paralleling the initial effects for the 13-day group. An analysis of variance comparing water intake during the feeding schedule for the last six days of the 6-day group with the first six days of the 13-day group only had a significant days effect $(F=6.14$, df $=5 / 50, p<.01)$ reflecting the gradual increase in water consumption that occurred in both groups. An analysis of variance comparing water intake during the feeding schedule for the last six days of both groups yielded a significant days effect $(F=8.183, \mathrm{df}=5 / 50, \mathrm{p}<.01)$ which interacted with the water availability condition $(F=5.854$, df $=5 / 50, p<.01)$. The 6-day group shows gradual development of polydipsia whereas the 13-day group maintains initially higher asymptotic water consumption, thus accounting for the interaction.

\section{Discussion}

Rats, on a distributed feeding schedule for several days during which eating but not drinking can occur, should have sufficient time to adapt to their schedule of feeding and, if adaptation to the feeding schedule is necessary for polydipsia to appear, they should show immediate excessive drinking when eating pellets is followed by drinking during the interpellet interval. But rats showed progressive increases in water consumption, and not an immediate effect, even though they were exposed to the feeding schedule for several days before having simultaneous access to pellets and water. This suggests that adaptation to the feeding schedule cannot adequately account for the gradual development of polydipsia.

\section{References}

CLARK, F. C. Some observations on the adventitious reinforcement of drinking under food reinforcement. J. exp. Anal. Behav., 1962, 5, 61-66.

FALK, J. L. The behavioural regulation of water-electrolyte balance. In M. R. Jones (Ed.) Nebraska symposium on motivation. Lincoln: University of Nebraska Press, 1961a. Pp. 1-33.

FALK, J. L. Production of polydipsia in normal rats by an intermittent food schedule. Science, 1961b, 133, 195-196.

FALK, J. L. Control of schedule induced polydipsia: Type, size, and spacing of meals. J. exp. Anal. Behav., 1967, 10, 199-206.

REYNIERSE, J. H. Excessive drinking in rats as a function of number of meals. Canad. J. Psychol., 1966, 20, 82-86.

SEGAL, E. F. The development of water drinking on a dry-food freereinforcement schedule. Psychon. Sci, 1965, 2, 29-30.

STEIN, L. Excessive drinking in the rat: Superstition or thirst? J. comp. physiol. Psychol., 1964, 58, 237-242.

STRICKER, E. M., \& ADAIR, E. R. Body fluid balance, taste, and postprandial factors in schedule-induced polydipsia. J. comp. physiol. Psychol., 1966, 62, 449-454.

Notes

1. This research was supported by the Research Council, University of Nebraska.

2. Now at the University of New Mexico. 